\title{
DESILUSÃO: IMPASSES CLÍNICOS E POLÍTICOS DIANTE DOS DILEMAS DE NOSSO TEMPO
}

\section{Disillusionment: Clinical and Political Impasses in the Face of the Dilemmas of our Time}

Desilusión: Problemáticas Clínicas y Políticas ante los Dilemas de nuestro Tiempo

Déception: Des Impasses Cliniques et Politiques Face aux Dilemmes de notre Époque

DOI: $10.5020 / 23590777 . r s . v 18 i E s p .6262$

Miriam Debieux Rosa (Lattes)

Prof. Associada do Instituto de Psicologia da Universidade de São Paulo (USP). Coordenadora do Laboratório Psicanálise, Política e Sociedade (IP-USP).

\section{Patrícia do Prado Ferreira (Lattes)}

Doutora em Psicologia Social pelo Programa de Estudos Pós-Graduados em Psicologia Social da Pontifícia Universidade Católica de São Paulo. Membro do laboratório Psicanálise, Política e Sociedade vinculado à Puc - SP e à USP.

\section{Rodrigo Alencar (Lattes)}

Doutor em Psicologia. Membro do laboratório Psicanálise, política e Sociedade vinculado à Puc - SP e à USP, membro do Dicourse Unity (UK).

\section{Resumo}

Acontecimentos sociais e políticos, nacionais e internacionais, têm abalado nosso cotidiano. Conquistas que pareciam sedimentadas na direção da democracia e nos temas relativos aos direitos humanos, conquistas sociais e considerações éticas na vida política, têm sido substituídas por chavões e discursos de ódio, racismo e xenofobia sob a lógica da guerra. Desse modo, têm sido enfrentados fluxos massivos de imigrantes, frutos de guerras e violências, atentados terroristas e uma tensão cotidiana em que o debate localiza no outro o perigo: generaliza-se a figura do terrorista. Vamos propor um deslocamento da lógica da guerra a fim de dialogar sobre a queda dos ideais e das ilusões e as dificuldades de traçar direções para o futuro. Vamos apontar o imbricado enlace entre ética do desejo, política e resistência à instrumentação social do gozo. Entendemos que perder um ideal é diferente de perder uma ilusão, crença ou delírio. A descrença, a desilusão, tem seus efeitos - um deles é agarrar-se à fantasia delirante. A idealização é um processo que envolve o engrandecimento e superestimação do objeto, não dizendo respeito ao ideal. A aflição psíquica nomeada "desilusão" estende-se dos ideais culturais (no plano do ideal-do-Eu) às expectativas do Eu (plano do Eu-ideal). Essa questão nos alerta para o encobrimento de outra ilusão, de autoengendramento, de poder superar a dependência simbólica ao Outro. Diferenciar esses termos nos permite apontar o imbricado enlace entre ética do desejo, política e a resistência à instrumentação social do gozo. Quanto à posição da psicanálise, retomaremos a frase de Lacan em Ciência e Verdade (1966/1998): "Por nossa posição de sujeito somos sempre responsáveis. Que chamem a isto como quiserem, terrorismo".

Palavras-chave: psicanálise; ideal; ilusão; política; resistência.

\section{Abstract}

Social and political events, national and international, have shaken our daily lives. Conquests that seemed to be set in the direction of democracy and on issues related to human rights, social achievements and ethical considerations in political life have been replaced by slogans and discourses of hatred, racism and xenophobia under the logic of war. In this way, massive flows of immigrants, fruits of wars and violence, terrorist attacks and a daily tension have been faced in which the debate finds in the other the danger: generalizes the figure of the terrorist. Let us propose a shift in the logic of war in order to talk about the fall of ideals and illusions and the difficulties of drawing directions for the future. Let us point to the overlapping link between ethics of desire, politics, and resistance to the social instrumentation 
of enjoyment. We understand that losing an ideal is different from losing an illusion, belief or delusion. Disbelief, disillusionment, has its effects - one of them is clinging to delusional fantasy. Idealization is a process that involves the enhancement and overestimation of the object, not referring to the ideal. The psychic affliction named "disillusionment" extends from cultural ideals (on the plane of the egoideal) to the expectations of the Self (plane of the I-ideal). This question alerts us to the cover-up of another illusion, of self-surrender, of being able to overcome symbolic dependence on the Other. Differentiating these terms allows us to point out the imbricated link between ethics of desire, politics and resistance to the social instrumentation of joy. Regarding the position of psychoanalysis, we shall return to Lacan's phrase in Science and Truth (1966/1998): "By our position of subject we are always responsible. Call it this way, terrorism. "

Keywords: psychoanalysis; ideal; illusion; policy; resistance.

\section{Resumen}

Acontecimientos sociales y politicos, nacionales e internacionales, vienen afectando nuestro cotidiano. Logros que parecían firmados en el rumbo de la democracia y en los temas relacionados a los derechos humanos, logros sociales y consideraciones éticas en la vida politica, vienen siendo sustituidos por clichés y discursos de odio, racismo y xenofobia bajo la lógica de la guerra. De este modo, flujo masivo de inmigrantes, fruto de guerras y violencias, ataques terroristas y una cotidiana tensión en la cual el debate localiza en el otro el peligro: se generaliza la figura del terrorista. Vamos a proponer un desplazamiento de la lógica de la guerra con la finalidad de dialogar sobre la caída de los ideales y de las ilusiones y las dificultades de trazar direcciones para el futuro. Vamos a enseñar la imbricada trama entre la ética del deseo, politica y resistencia a la instrumentalización social del gozo. Entendemos que perder un ideal es diferente de perder una ilusión, creencia o delirio. La incredulidad, la desilusión, tiene sus efectos - uno de ellos es agarrarse a la fantasía delirante. La idealización es un proceso que envuelve el engrandecimiento y la súper estimación del objeto, sin relación con el ideal. La angustia psíquica nombrada "desilusión" se extiende de los ideales culturales (en el plan del ideal-del-yo) a las expectativas del Yo (plan del Yo-ideal). Esta cuestión nos alerta para el encubrimiento de otra ilusión, de auto creación, de poder superar la dependencia simbólica del Otro. Diferenciar estos términos nos permite apuntar la imbricada trama entre ética del deseo, política y la resistencia a la instrumentación social del gozo. Cuanto a la posición del psicoanálisis, retomaremos la frase de Lacan en Ciencia y verdad (1966/1998): "Siempre somos responsables por nuestra posición de sujeto. Que llamen esto como quieran, terrorismo".

Palabras clave: psicoanálisis; ideal; ilusión; política; resistencia.

\section{Résumé}

Des événements sociaux et politiques, nationaux et internationaux, troublent notre vie quotidienne. Des réalisations qui semblaient consolidées vers la démocratie et chez les droits l’homme; bien comme des réalisations sociales et de la pensée éthique dans la vie politique, sont remplacées par des discours de haine, de racisme et de xénophobie sous la logique de la guerre. De cette façon, des flux massifs des immigrés, des fruits de la guerre et de la violence, des attaques terroristes et une tension quotidienne sont confrontés. Cela se passe dans le débat qui montre le danger dans l'autre: de la généralisation de la figure du terroriste. Dans cet article on propose un décalage de la logique de la guerre avec l’objectif de discuter de la chute des idéaux, et des illusions, bien comme des difficultés de tracer directions pour l'avenir. On signale la liaison compliquée entre l’éthique du désir, la politique et, aussi, la résistance à l>instrumentation sociale de la jouissance. On comprend que perdre un idéal est différent de perdre une illusion, de la croyance ou de l'illusion. Lsincrédulité et la désillusion ont ses effets - lıun de ces effets est s>attacher à une fantaisie délirante. L〉idéalisation est un processus qui contourne l>agrandissement et la surestimation de l>objet, sans faire rapport à l>idéal. L〉affliction psychique appelée «désillusion» s>étend des idéaux culturels (sur le plan de lidéal du Moi) aux attentes du Soi (plan idéal du moi). Cette question attire attention au camouflage d)autre illusion, d'auto-engendrement, de la possibilité de surmonter la dépendance symbolique de l>Autre. Différencier ces termes nous permet de montrer la liaison compliquée entre l'éthique du désir, la politique et, aussi, la résistance à l'instrumentation sociale de la jouissance. À propos de la position de la psychanalyse, on reprend la phrase de Lacan dans «La Science et la vérité» (1966/1998): «De notre position de sujet, nous sommes toujours responsables. Qu>on appellent cela où l>on veut, du terrorisme.».

Mots-clés: psychanalyse; idéal; illusion; politique; résistance. 


\section{O Terror Atormenta o "fim da história"}

Não é exagerado afirmar que o continente europeu realmente acreditava ter alcançado o "fim da história", como proposto por Fukuyama, $(1989,1992)$, pois a ideia que poderia se 'ver' consolidada era a de que estaríamos diante do fim da evolução ideológica, especialmente em razão do 'triunfo' da democracia liberal. A visão de que um Estado de bemestar social seria permanente na Europa fez com que fosse atribuída certa turbulência própria ao movimento da história apenas do lado de fora das fronteiras da União Europeia e dos Estados Unidos. No entanto, a crise econômica disparada em 2008 e o reinício de ações terroristas, em 11 de setembro em 2001, deram novo fôlego para as incertezas sobre o futuro.

Em resposta aos ataques ocorridos em 11 de setembro nos Estados Unidos, uma nova dinâmica à ideia de segurança nacional e guerra foi instituída. A guerra ao terror, apropriada como uma 'guerra preventiva', elegeu uma série de exceções aos tratados internacionais que agora arbitram sobre o tema. Dentre estas, temos a suspensão dos direitos dos prisioneiros de guerra, concretizada na prisão de Guantánamo, e um clima de paranoia generalizada em que qualquer um pode ser o inimigo.

Essa questão se atualiza com a disseminação do medo e a declaração genérica de guerra feita por François Hollande a partir do ataque terrorista ocorrido em novembro de 2015, em Paris, seguida da ascensão de Donald Trump ao governo dos Estados Unidos, em 2016, baseada num discurso racista e xenófobo. Trump culpabiliza os imigrantes pelas dificuldades econômicas e sociais do país, tendo proposto o fechamento das fronteiras - ilustrado pelo decreto que assinou no final de janeiro de 2017, em que proíbe a entrada de refugiados e cidadãos de sete países (de maioria muçulmana): Iraque, Síria, Irã, Sudão, Líbia, Somália e Iêmen, e pela continuação da construção do muro que separa as fronteiras dos Estados Unidos com o México.

Os acontecimentos no Brasil também indicam a precariedade do debate político, que passa a ser delineado pelos discursos do ódio, racismo e da xenofobia, promovendo tensão social e incerteza não apenas quanto ao futuro econômico do país, mas também social e político, em especial ao relativo à população social e economicamente marginalizada. A polarização intensa dos três últimos anos (2014, 2015 e 2016), a disputa eleitoral para presidência e prefeituras, as medidas tomadas pelo governo de Michel Temer em nome do bem-estar (especialmente o financeiro) e as discussões que as sucederam, e até mesmo a lei 'antiterrorismo', sancionada em 2015, indicam uma retomada ordenadora e progressista que retira direitos e mantém privilégios.

A política de restaurar a segurança pela lógica da guerra deixa fora da cena o contexto histórico, econômico e político produtor das tensões sociais e dá margem a uma política repressiva e ao estado de alerta que suspendem os habituais direitos perante uma acusação. Assustada, parte da população apoia algumas dessas medidas e acirra a resistência em receber os imigrantes - esses milhares de pessoas que são tomadas como suspeitas de terrorismo simplesmente por sua condição de imigrante. Estabelecido quem é o inimigo, o combate leva a abandonar conquistas que pareciam sedimentadas na direção da democracia e nos temas relativos aos direitos humanos, conquistas sociais e considerações éticas na vida política, e o que resta são discursos que se sustentam a partir do racismo, do ódio e da xenofobia, sob a lógica da guerra que elege o inimigo, o terrorista, o bárbaro contemporâneo, ou aqueles que denunciam o fracasso do 'fim da história'.

\section{O Bárbaro Contemporâneo e a Lógica da Guerra}

Como bem lembrou Alain Badiou em Nosso mal vem mais de longe (2016), o ex-presidente dos Estados Unidos, Barack Obama, declarou na ocasião do atentado em Paris que se tratava de um crime contra a França, contra Paris e contra a humanidade. Apesar da nobreza de suas declarações, o que fica claro é que ele não fez isso em todos os acontecimentos desse tipo, como nos ataques terroristas no Iraque, Paquistão ou Nigéria. Essa declaração, de acordo com Badiou, "contém a ideia, supostamente óbvia, que esta humanidade assassinada reside antes na França, e sem dúvida também nos Estados Unidos, do que na Nigéria ou na Índia, no Iraque, no Paquistão ou no Congo" (para.09).

E continua: "na verdade, Obama quer nos lembrar de que para ele a humanidade é de saída identificável ao nosso bom e velho Ocidente. Pode-se bem-dizer: Humanidade = Ocidente". O que, como afirma com precisão, assume um caráter identitário que coloca em oposição 'bárbaros e civilizados', como se deixasse entender "mesmo que indiretamente, que há partes da humanidade que são mais humanas do que outras" (Badiou, 2016, para.10).

Desse modo, notícias sobre naufrágios de barcos de refugiados se sobrepõem àquelas sobre ataques terroristas, sugerindo uma relação entre ondas de refugiados e a destruição do bem-estar do cidadão europeu médio, colocando que o Ocidente, em definitivo, é o lugar dos civilizados (Badiou, 2016).

Žižek (2015) também indica o que está sendo colocado à vista a partir dessa escolha daquele que é ou não é considerado:

Apesar de toda obscuridade em torno do influxo dos refugiados na Europa, muitos deles sem dúvida tentam escapar condições terríveis de seus países. Um dia após os ataques de Paris, um deles secamente comentou na TV: "Imagine uma cidade como Paris 
em que o estado de exceção que reina lá hoje é simplesmente uma característica permanente da vida cotidiana por meses, quando não anos. É disso que estamos fugindo." Não podemos ignorar o momento de verdade dessa afirmação (Žižek, 2015, para.11).

Nessa direção, retomamos Benjamin (1994), quando afirma que "a tradição dos oprimidos nos ensina que o 'estado de exceção' em que vivemos é na verdade a regra geral. Precisamos construir um conceito de história que corresponda a essa verdade.” (p. 226). Em Agamben (2004), o Estado de exceção elege a figura de exceção - o outro, pura vida nua, matável. Em sua trilogia sobre o Homo sacer, Agamben debate a noção de campo como paradigma da política no contemporâneo: modalidade de organização positivada a partir da supressão do ordenamento jurídico, que produz, a partir da lógica de exceção, sujeitos legalmente inomináveis. O espaço do campo é o que emerge nessa área de exceção e o que irá fazer a intersecção entre o dentro e o fora do ordenamento. As modulações na ideia de campo caracterizam o capitalismo global e se efetivam ao amontoar em guetos e favelas todos aqueles que se constituem figuras de exceção do nosso tempo. Nesse contexto de debate, interessa-nos abordar a figura do muçulmano como emblemática do estado-limite ao qual chegaram algumas pessoas em condições de exclusão social. Segundo Agamben, são as pessoas que estão fora do ordenamento jurídico, os "matáveis", uma vez que sua morte não gera comoção social ou mesmo luto.

Poderíamos dizer que o bárbaro contemporâneo, ou mais exatamente o Homo sacer, seria o terrorista? Estamos falando que, descolada dos atentados terroristas, criou-se uma nova nomeação às figuras de exceção e o termo terrorista disseminouse - terrorista é o outro.

O outro encarna o mal — numa falsa divisão, numa dicotomia que assim se processa: outro/mau e eu/bom. A dicotomia evita a necessária divisão processada em cada um, em que o bom e o mau habitam. Um exemplo de onde podemos ver essa ideia em imagem é, ainda, nos meios de comunicação em massa, em que os 'valores' são estabelecidos pelo Ocidente enquanto o perigo vem além das fronteiras. O outro fica responsável pela não realização das idealizações graças às quais é possível viver em uma sociedade, como se sua presença obstruísse uma satisfação plena. O que acontece é o que poderíamos chamar de uma 'privatização' do gozo, isto é: é parte do gozo que ele seja próprio, que não seja compartilhado, que o 'outro' não o tenha. No entanto, como alertam Mountian e Rosa, "o outro aqui não será considerado apenas em relação à posição do excluído no discurso, mas também como constitutivo da norma. O outro, portanto, também cria o espaço discursivo que define o que somos nós" (2015, p. 154).

Observar as estratégias de manipulação política pelos afetos não individualiza a questão. Nessa direção, podemos dizer que, nessa guerra ao terror, muito se aplica ao que afirma Alencar (2012): “. . . a guerra - inclusive a guerra às drogas - não deve ser vista como manifestação de ódio irracional, mas como meio para atingir determinados interesses nem sempre declarados. As práticas bélicas são estratégias permeadas de objetivos políticos que mesmo em tempos de conflito se mantém em processo de negociação - onde alguns interesses de seus participantes podem ser declarados e outros não" (p. 21).

Desse modo, a política alimenta um discurso sobre o outro/imigrante/ terrorista/craqueiro/etc. como aquele que rouba o trabalho e/ou o lazer que seria desfrutado pelo autóctone. Instala-se uma lógica paranóica de acusação ao outro, esse que atrapalha o imaginário de viver em um estado de bem-estar social, saúde integral e felicidade. Essa lógica induz a certezas sobre a necessidade de expulsar quem atrapalha tal ilusão: a ilusão de supor uma sociedade pronta, acabada e sem conflitos. Sem transformação. Uma sociedade vivendo, portanto, a ilusão do "fim da história".

Se estivermos no fim da história, se chegamos ao ponto ideal, não há no horizonte uma proposta de pacto social, mas a ideia de um retorno ao bem-estar de alguns que supõe calar o mal-estar dos outros. Isto posto, podemos afirmar que um pacto social é muito diferente do tratado de guerra realizado pelo vencedor, que dá algumas concessões ao perdedor da guerra suficientes para escravizar e impedir que seu ressentimento desemboque na revolta. Um pacto social tem a lógica de uma aliança para compor uma sociedade entre diferentes, na qual cada um tem seu quinhão de gozo e perda.

Para esclarecermos melhor esse problema, lembremos que Freud tece sua interpretação acerca do funcionamento social na qual o indivíduo passa a adiar suas satisfações, bem como substituir os objetos almejados, visando à estabilidade dos vínculos grupais. É sob essa perspectiva que temos a interdição do incesto, assim como leis matrimoniais ou restrições ao homicídio. No entanto, ao avançarmos para além das comunidades tribais, temos uma peculiaridade das sociedades ocidentais que nos impele a questionar os elementos presentes nas guerras ao terror. Essa peculiaridade diz respeito ao seu valor 'democrático'. Nas sociedades ocidentais, exalta-se a democracia enquanto valor universal, de modo que a sociedade enquanto tal seja receptiva às diferentes culturas de povos de outras regiões do mundo. O modo como vem sendo travado o combate ao terrorismo tem operado de modo indutivo, caracterizando povos e culturas como terroristas, de modo que a ameaça não seja circunscrita por um ato, mas pelo pertencimento à determinada nacionalidade ou etnia.

A questão que se insere no nosso contexto atual diz respeito à estratégia da guerra para enfrentar o que denominamos segurança ou, melhor dito, a quem se impõe o risco ou a violência estatal para que uma parcela da população esteja segura? 


\section{Guerra e Política}

Alencar (2012) desenvolveu em seu trabalho Por que a guerra às drogas? Do crack na política ao crack do sujeito uma série de hipóteses sobre a lógica da guerra, particularmente da guerra às drogas. Pensamos que seu desenvolvimento ilumina a estratégica política em jogo ao nomear um inimigo gerador do mal-estar social. Seguimos com as concepções desse trabalho.

O autor afirma, com base na seguinte citação de Jacques Lacan, que uma das principais funções operantes em nossa sociedade é a troca, pois

qualquer um, a todo instante e em todos os níveis é negociável, pois o que nos dá qualquer apreensão um pouco séria da estrutura social é a troca. A troca de que se trata é a troca de indivíduos, isto é, de suportes sociais, que são ademais o que chamamos de sujeitos, com o que eles comportem de direitos sagrados, diz-se, à autonomia. Todos sabem que a política consiste em negociar e, desta vez, por atacado, aos pacotes, os mesmos sujeitos, ditos cidadãos, por centenas de milhares. (Lacan, 1964/1985, p. 13)

Na visão da política como operação de troca e negociação, Alencar (2012) considera que a guerra tem sua função dentro da política como estratégia e prática que definem qual será esse poder de negociação. É por meio das tecnologias e dos territórios conquistados que aquele que se favorece da guerra adquire maior poder nas relações de troca. Dessa forma, aquele que se impõe pela via das armas pode ditar aos seus aliados e inimigos quais são os termos que regem as operações comerciais. Por conseguinte, o famoso aforismo de Clausewitz, no qual "a guerra é uma simples continuação da política por outros meios" é seguido pela seguinte afirmação "vemos, pois, que a guerra não é só um ato político, mas um verdadeiro instrumento político, uma continuação das relações políticas, uma realização destas por outros meios" (1832/2010, p. 27). Portanto, compreendemos a guerra como um instrumento político, e não a exceção de quando não há política.

A guerra favorece o estreitamento dos laços libidinais entre determinado grupo, baseado em um ideal de eu que os sustenta, assim como na submissão baseada em uma fé cega, trabalhada por Freud como uma hipnose (1921/2006). Tal submissão pode levar aos atos mais violentos e vis, ou à aprovação de qualquer ato do líder, para ter garantido o seu amor e, desse modo, o grupo se exime da responsabilidade da escolha sobre seus próprios atos. Por sua vez, como alerta Freud (1932/1997), alguém que adere às decisões de atacar outra nação ou grupo pode ter diversos motivos, uns declarados e outros latentes, que talvez nunca venham à tona.

O autor recorre à Psicologia das massas e análise do eu (Freud, 1921/2006), texto que aborda o contágio do medo em um grupo e suas formas de organização diante de um inimigo:

Tomando a palavra 'pânico' no sentido de medo coletivo, podemos estabelecer uma analogia de grandes consequências. No indivíduo o medo é provocado seja pela magnitude de um perigo, seja pela cessação de laços emocionais (catexias libidinais); este último é o caso do medo neurótico ou angústia. Exatamente da mesma maneira, o pânico surge, seja de um devido aumento do perigo comum, seja ao desaparecimento dos laços emocionais que mantém unido o grupo, e esse último caso é análogo ao da ansiedade neurótica (Freud, 1921/2006, p. 61).

A cessação de laços emocionais e o aumento de um perigo comum não necessariamente devem ocupar lugares opostos. Uma sociedade pode se sentir unida tendo que enfrentar um inimigo. Isso ocorre quando seus membros, em sua maioria, o reconhecem enquanto tal. Diante do enfrentamento desse inimigo, posições de liderança podem ser reconhecidas, apontando por quais meios esse inimigo deve ser atacado e quão importante é a união do grupo.

A elucidação da construção do inimigo segue uma lógica na qual antecedem ao pânico certas torções em relação ao objeto desse pânico. No caso do combate ao terror, é uma construção na qual determinada cultura deteria, em seu cerne, na razão de sua existência, uma perspectiva inerentemente antioriental, de modo que todos os membros pertencentes a essa cultura seriam portadores dessa crença. A partir de então, temos a produção do horror a esse objeto, a disseminação pelas propagandas e mídias do outro como ameaça ao bem-estar social e, por fim, a política de esforços de supressão da circulação dessa figura.

$\mathrm{O}$ autor conclui que: "Periodicamente, há uma renovação daquele que habita o lugar de inimigo, fazendo com que surja uma nova substância ocupando o lugar de uma ameaça... Em diversos momentos ao longo do último século . . . criam-se meios de identificar os inimigos, bem como acusá-los de desintegradores do laço social” (Alencar, 2012, p. 91).

O processo de delineamento de um inimigo por meio da diferenciação e estratificação de diferentes culturas é exposto por Mountian e Rosa (2015). As autoras demonstram como a ideia de multiculturalismo opera enquanto versão repaginada de um racismo que irá ocorrer sob outros termos, onde é possível questionar como 'raça' e 'cultura' são colocadas e utilizadas no discurso. De fato, Žižek (1997) comenta:

Sem o real do gozo, o Outro permanece em última instância uma ficção, um sujeito puramente simbólico de racionalização 
estratégica exemplificada na "teoria da escolha racional". Por essa razão, se é tentado a substituir o termo "multiculturalismo" por "multirracismo": o multiculturalismo suspende o centro traumático do Outro, reduzindo-o uma entidade folclórica asséptica1 (p.26).

Segundo Walter Benn Michaels (1992): "Nosso senso de cultura é caracteristicamente tomado (meant) para deslocar (displace) raça, mas ... a cultura se tornou uma maneira de continuar ao invés de repudiar o pensamento racial”2 (p. 125).

Esses são aspectos cruciais, ou seja, raça e cultura são termos usados de uma maneira específica e, nesse sentido, é possível ver a substituição de raça por cultura, mantendo os mesmos regimes de diferença. Nesse caso, a reiteração de posições específicas do outro.

No dia 2 de setembro de 2015, a foto de Aylan Kurdi, de três anos de idade, morto nas areias de uma praia turca, percorreu o mundo sensibilizando as pessoas para a questão. A partir dessa sensibilização, seguiu-se um imenso debate (inclusive inflamado pelas redes sociais) acerca da crise dos refugiados e da importância de acabar com o descaso presente na política migratória da União Europeia. Apenas dois meses após a divulgação da foto de Aylan, o mundo transmitia ao vivo os ataques terroristas executados em Paris, na fatídica noite de 13 de novembro. Um dia após os ataques, a imprensa internacional noticiou um passaporte sírio encontrado em um dos locais dos atentados, levantando suspeitas sobre a recente onda de refugiados como uma espécie de canal de acesso a possíveis terroristas que destruiriam a França e sua cultura a partir do interior de seu território.

Se antes o corpo sem vida de uma criança denunciava a brutalidade do descaso da política ocidental perante os conflitos nos quais participam seus próprios interesses, pouco tempo depois esse mesmo corpo foi convertido em um terrorista em potencial, e, portanto, numa ameaça. Dessa forma, sensibiliza-se e dessensibiliza-se. O suposto discurso realista sempre recorre às conclusões equivocadas e precipitadas para promover um fechamento para o outro. O que antes era uma crise que dizia respeito a todos, passa a ser visto como um mal necessário para preservar os "valores de nossa civilização". Assim, Aylan Kurdi volta a ser um dano colateral da luta contra o terror perante a opinião pública. Essa é a operação de conversão, em que um suposto realismo se converte em um discurso totalitário e elege o inimigo a ser enfrentado.

Demos destaque à manutenção de uma política do medo e à necessidade de sustentação de uma ameaça imaginária como estratégia de tamponamento do mal-estar inerente à vida social. Nesse sentido, a universalidade do valor à vida fica em xeque.

Deparamo-nos com um desafio: como construir uma polis em que homens e mulheres não sejam supérfluos - ao menos uns mais supérfluos que outros?

Nessa direção, propomos um diálogo sobre a queda dos ideais e das ilusões e as dificuldades em traçar direções para o futuro. Vamos apontar o imbricado enlace entre ética do desejo, política e a resistência à instrumentação social do gozo.

\section{Ilusão/Desilusão e os Ideais}

Vamos avançar no esclarecimento das estratégias políticas que se apoiam nos afetos, particularmente no medo e desamparo, que contribuem para sustentar um discurso "realista" sobre a necessidade da segurança e da guerra ao terror. A convicção de uma realidade perigosa produz um falso impasse entre seguir sustentando os ideais e valores da sociedade e proteger-se dos que a ameaçam. Impasse falso, na medida em que os conflitos sociais e políticos que geram as violências não são levados em conta. Em vez disso, seguem a descrença e desilusão perante a sustentação da sociedade nos valores da civilização e o sentimento de insegurança que, por vezes, passa a gerir a aceitação de políticas segregacionistas.

Rosa (2016) explicita essa estratégia política da seguinte forma:

o discurso social e político, carregado de interesses e visando manter ou expandir seu poder, mascara-se de discurso do Outro (campo da linguagem) para capturar o sujeito em suas malhas - seja na constituição subjetiva, seja nas circunstâncias de destituição subjetiva. Tal discurso visa confundir o impossível (relação com a morte e com o desejo como falta) com o proibido (relação com as leis sociais), para governar o sujeito e sua trajetória na cena familiar, social e política e para incidir sobre sua constituição seu enlace em novos grupos, sua reorganização subjetiva, seu embate com as leis (p. 23).

Confundir o discurso de uma sociedade com o discurso simbólico facilita produzir uma dicotomia entre bons/civilizados e maus/bárbaros. Entendemos que nesse processo há um deslocamento dos ideais civilizatórios para os ideais do eu, centrados

1 Without the element of the real of jouissance, for here the Other ultimately remains a fiction, a purely symbolic subject of strategic reasoning, as exemplified in the "rational choice theory." For that reason, one is even tempted to replace the term "multiculturalism" with "multiracism:" multiculturalism suspends the traumatic kernel of the Other, reducing it to an asepticized, folklorist entity.

2 "Our sense of culture is characteristically meant to displace race, but ... culture has turned out to be a way of continuing rather than repudiating racial thought". 
no narcisismo de um grupo que naturaliza a segregação.

Em Desilusão da guerra, a primeira parte do texto de Freud Reflexões para tempos de guerra e morte (2009), ele descreve como é insuportável para o homem europeu moderno o reconhecimento de sua crueldade. A desilusão indicada no título se refere à capacidade das nações e indivíduos de tratarem o estrangeiro com o máximo de crueldade. Portanto, aquilo que não parecia possível para as civilizações/nações que dominam o bemestar do mundo, mostra-se possível na guerra. De certo modo, retomamos que é, justamente, sobre esse ponto que Freud (1930/1997) alerta que as técnicas de domínio tornam os homens semelhantes a deuses. Mas eles não se tornam mais felizes, pois a civilização, ao se aperfeiçoar (podemos dizer que com a ordem e o progresso), torna-se violenta e destruidora. Nesse momento, ele se refere à desilusão com as nações civilizadas, diferente da que constatamos atualmente, em que a desilusão parece ser com o pacto civilizatório, uma derivação importante.

Tem sido essencial ao processo civilizador a construção de uma concepção de mundo que sintetiza, organiza e soluciona os problemas da existência. Essa é a função das grandes referências construídas na história da humanidade — dos livros que dão força às narrativas nas quais se sustentam as diretrizes gerais do campo civilizatório e também as religiões e a ciência. No entanto, tais referências organizadoras podem ser reduzidas, segmentadas, e compor distorções que as transformam em ideologias, ou no cientificismo que promete superar a morte, atingir a imagem perfeita, o desempenho ideal, a felicidade toda.

Podemos pensar como uma proposta de pacto civilizatório as diretrizes sobre os direitos fundamentais do homem, depois da segunda guerra, quando a Organização das Nações Unidas (ONU) promulgou a Declaração Universal dos Direitos Humanos, em dezembro de 1948.

No entanto, podemos incluir como segmentação, e não como pacto social, a convicção citada no início deste texto de termos alcançado o "fim da história", para consolidar a ideia de que estamos diante do fim da evolução ideológica, especialmente em razão do 'triunfo' da democracia liberal no Ocidente. Mais do que um pacto, podemos chamar tal convicção de indução à crença.

Da função da crença, diz Freud, em O futuro de uma ilusão (1927/2006): "Psicologicamente falando, estas crenças apresentam o fenômeno da realização do desejo. Desejos que são as 'realizações dos desejos mais antigos, mais fortes e mais urgentes da humanidade"” (p.38). Entre esses desejos, podemos destacar a necessidade de agarrar-se à existência do pai, ao pensamento de certa expansão da vida terrena com a ideia de uma pós-morte ou até mesmo da imortalidade. E sempre há quem se ofereça para ocupar esse lugar do pai e comandar segundo sua vontade, assim como quem queira segui-lo.

As crenças podem ser apresentadas não na figura do pai/líder, mas apoiadas em ideias supostamente racionais e realistas. No entanto, estão mais próximas do delírio do que da fantasia, uma fantasia delirante. O termo fantasia delirante, utilizado no ensaio sobre a Gradiva (Freud, 1907/1976, p.43), expressa as delicadas intersecções entre uma gama de termos, tais como: ilusão, crença, alucinação, fantasia e delírio. O seu contraponto serão as controversas relações com a realidade e racionalidade.

Podemos "chamar uma crença de ilusão quando uma realização de desejo constitui fator proeminente em sua motivação", afirma Freud (1927/2006, p.31). Portanto, o foco está no desejo, assim como nas formas de lidar com o desamparo humano. A religião será o modelo para indicar um "tesouro de representações, engendrado pela necessidade de tornar suportável o desamparo humano" (Freud, 1927/2006, p.18). Certas crenças apoiadas pela coletividade podem promover, dado o modo de certeza e conviç̧ão, o fanatismo, pois nada demove um fanático quando uma crença o protege do desamparo e ele pode destruir aqueles que não o acompanham nessa crença.

A aflição psíquica nomeada "desilusão", apontada no título do artigo de Freud sobre a guerra, pode se estender tanto aos ideais culturais (no plano do ideal-do-Eu) como à mortalidade do Eu (plano do Eu-ideal). Perder um ideal é diferente de perder uma crença ou delírio. Deparar-se com os descaminhos da sociedade, com a descrença, com a desilusão, tem efeitos na humanidade e novos pactos podem ser construídos. Confundir um com o outro compõe a instrumentalização política do sujeito pela via das paixões. Mais especificamente, produz desiludidos convictos que podem eliminar o mal-estar social, o que substitui ou apaga a árdua função civilizatória do ideal.

Desiludir é, ainda, agarrar-se à fantasia delirante; é manter a ilusão sob a forma de frustação e ressentimento. Sem que opere a castração, fica mantida a ilusão e elidido o ideal. A mistura dessas instâncias generaliza a desilusão e veda as possibilidades de outros caminhos na direção do despertar das alienações. O desiludido quer se iludir novamente e o seu olhar fascinado alimenta o ódio passional ao outro. Desse modo, aquele que encarna o porta-voz dos desiludidos termina por ser assimilado como "realista", o que tem efeitos politicamente conservadores e, ao mesmo tempo, devastadores para um importante fluxo de mudanças sociais. O desiludido quer se iludir novamente e facilmente restitui a ilusão na lógica dualista e narcísica de vítima-culpado. Nessa direção, estará a construção do inimigo responsabilizado por suas perdas.

Essa questão nos alerta para duas direções. Uma é a promoção do império da noção de indivíduo, que alimenta a concepção de autoengendramento e a ilusão de poder superar a dependência simbólica ao Outro, campo da linguagem e da cultura. Essa dimensão não diz respeito a um ideal, mas à idealização, processo que envolve o engrandecimento e superestimação de si mesmo.

Outra direção refere-se ao ideal do eu, que indica a demarcação simbólica de uma posição na relação com os outros, indicada por um traço com valor de significante. $\mathrm{O}$ ideal do eu, embora fundado narcisicamente e pelo desejo do Outro, indica a 
demarcação simbólica que possibilita os laços sociais, sustentados pelo desejo e pelo traço das identificações. O ideal forma-se e transforma-se a partir do laço civilizatório. Dessa forma, não há supressão do laço com o outro, nem escravização dele. Essa concepção de ideal é radicalmente diferente das de fascinação e alienação a uma crença/ideia de um grupo tomado como coletivo.

O discurso dito realista faz uso do desejo de ilusão e estimula a crença em fatos ditos objetivos, impondo a adesão do sujeito a seu discurso. Responsabiliza (e odeia) os que não se adaptam por sua impossibilidade de serem plenos e felizes, e a ameaça ao seu modo de organizar-se socialmente amplia-se para uma ameaça à civilização. A estratégia desse discurso totalitário é limitar as alternativas do sujeito a uma suposta realidade, isto é, o que paralisa os processos criativos e desresponsabiliza o sujeito da apreciação própria e de seu compromisso.

Rosa (2016) continua o argumento:

O discurso do poder intensifica a certeza do eu, invalidando a verdade do sujeito que se torna louco, atrasado, bandido ou doente - nomes da exclusão pelo bem do outro. O outro, portanto, confunde-se com o inimigo que ameaça e deve ser eliminado. Mas, não há como eliminar a verdade que sua presença enuncia, pois não é possível eliminar o real. (p. 45)

Essa é uma chave para pensar a intolerância e os preconceitos presentes nos discursos totalitários. A convicção da exterioridade tenta mascarar o vazio ao redor do qual se estruturam as relações sociais (Alemán, 2013) e as várias formas de compor uma sociedade. Assim, trata-se de uma impostura defender a concretude, a realidade de um modo específico e datado de contornar esse vazio - ou defender que há apenas um modelo civilizado, melhor para todos.

Cabe refletir se a conjuntura atual indica uma tendência a obturar o mal-estar social impondo as realidades de uma estrutura já dada. Estaríamos no mundo realista, um mundo de desiludidos, no império da ilusão? Este é um ponto de debate ao qual contribuímos com uma faceta na direção da resistência às estratégias da política dos afetos. Para além do mundo de desiludidos, como despertar do sono da ilusão para a aventura do desejo e para traçar perspectivas de futuro?

\section{Um mais além das Ilusões: O Despertar (Descartes vs. Chuang-Tsé)}

Um dos maiores legados da sociedade ocidental pode ser situado por uma das principais referências do pensamento iluminista. René Descartes traçou as bases de uma razão que não toleraria nada que estivesse além de seus limites. Em seu Discurso sobre o método, traça as diretrizes nas quais pôde apoiar sua afirmação. Segundo o filósofo, sua terceira máxima era:

procurar sempre vencer antes a mim mesmo do que a fortuna, e mudar meus desejos do que a ordem do mundo; e, de maneira geral, acostumar-me a crer que nada está inteiramente em nosso poder a não ser nossos pensamentos [ênfase adicionada], de modo que, tendo feito o melhor no tocante às coisas que nos são exteriores, tudo o que não podemos conseguir é, para nós, absolutamente impossível (Descartes, 1937/2010, p. 62).

É perante a impossibilidade do exercício de poder e controle sobre si e os próprios pensamentos que Freud irá desenvolver seu trabalho sobre o inconsciente e, mais especificamente, sobre a teoria do sonho. É mediante o impossível que o sujeito deseja e produz algo que ex-siste em relação a si. Lacan, no Seminário 11: O avesso da psicanálise (1964/1985), e, depois, Žižek (1996), lançam mão do paradoxo do sábio Chuang-Tsé para discutir a divisão subjetiva, o sujeito habitado pela exterioridade da rede simbólica e o desejo que dá direções à existência. Ao acordar após ter sonhado que era uma borboleta, Chuang-Tsé se pergunta se não era a borboleta que havia sonhado ser Chuang-Tsé. Ele não é louco, nos diz Lacan, porque não se toma por absolutamente idêntico a Chuang-Tsé. Essa identidade de Chuang-Tsé é para o outro, como ele comparece na rede simbólica. Mas ele é também borboleta no seu desejo, ou seja: o que lhe confere singularidade é ser borboleta. No sonho, ele desperta para o desejo. Ao acordar, dorme, aliena-se em Chuang-Tsé.

Esse é o paradoxo que questiona a supremacia da razão, ou da realidade, em detrimento do desejo. Por essa via, cabe considerarmos que o que se institui como a "realidade" está sempre configurado por meio dos significantes que modulam nossa percepção. De acordo com Lacan (citado por Žižek, 1996, p.323), "a realidade é uma construção fantasiosa que nos permite mascarar o Real de nosso desejo". Se considerarmos a realidade como precária e inacabada, cabe ao desejo interrogála por meio de suas impossibilidades. A fantasia social leva à objetividade fantasmática, à ideologia, definida como "uma fantasia social que estrutura a determinação do valor e da significação da realidade socialmente compartilhada. Fantasia social capaz de produzir uma 'objetividade fantasmática' que tem um nome próprio: ideologia” (Safatle, 2002, p.188).

Isso difere da perda de uma idealização que aliena o jogo livre e criativo do desejo, como o desejo de voar de Chuang-Tsé, manifesto em seu sonho. O que seria da ciência sem o desejo de voar, de ir à lua, de flutuar sobre as águas, de atravessar fronteiras?

Delineiam-se outras formas de entender a política. 
A política apresenta-se em duas faces: não apenas como poder e domínio sobre o sujeito, mas também como a ação no espaço entre as relações, ou seja, aquela que tem no horizonte a produção do mundo comum. A condição do comum é sustentar um lugar vazio como um espaço que possibilita a criação. O comum e as formas que tomam a comunidade são inscrições das construções que se fizeram em torno desse vazio. Desenha-se uma compreensão de política calcada na experiência com o outro, produzida na transmissão que supõe a priori a diferença e a pluralidade (Rosa, 2016, p.23).

Nessa direção, o problema entre tentar sair da ideologia ou "desmascarar a realidade" envolve uma série de impasses, um dos quais foi bem-exemplificado por Žižek quando ele aponta que os fatos podem se adequar às premissas. Assim, um alemão razoável, na década de 30, poderia se convencer de que seu vizinho judeu gentil e afável somente agia assim por ser manipulador e pernicioso, ocupando, desse modo, o lugar de ameaça.

Portanto, para pensar a intolerância e os preconceitos, não basta uma intenção de não ser intolerante, mas de pensar a função do preconceito no campo subjetivo e no campo social (Žižek, 1996). Como este afirma, existe certa incapacidade em nos desfazermos de nossos preconceitos ideológicos, pois o "constructo ideológico sempre esbarra em seus limites no campo da experiência cotidiana" (p.75).

Nesse sentido, a psicanálise aposta em um mais além das ilusões, em um trabalho de remissão do sujeito à verdade de seu desejo, que o remete à historicização de seu desejo e à consequente abertura para a criação de novos sentidos da existência no campo do comum.

A psicanálise, em vez de adaptação à realidade, enfatiza o encontro com o real pulsional, traumático, pois constata que o objeto do desejo não existe na realidade. O sujeito se depara com a sua condição trágica — não há um sentido prévio para a existência, pois ele está marcado por uma falta constitutiva que o lança na direção do Outro. Não há garantia seja no pai/ líder, nas convicções ou na harmonia entre os homens; não há imortalidade, e a paz é uma aposta e conquista.

Freud (2009) repropõe o ditado latino: Si vis pacem, para bellum (Se queres paz, prepara-te para a guerra) e sugere: $S i$ vis vitam, para mortem (Se queres a vida, prepara-te para a morte). A mortalidade, o maior dos ataques narcísicos, organiza a vida. Conforme afirmaram Rosa, Carignato e Berta (2006), "o lugar vazio no Outro não enuncia a lei. Cabe, pois, ao sujeito, enunciá-la e tomá-la como esteio que determina o lugar do gozo" (p.46). A proposição envolve implicação e responsabilidade por seu inconsciente e pela lei que nele se articula. Só lhe resta criar, dar contorno, dar bordas, ao que não tem bordas.

É nessa direção que retomamos Lacan em A Ciência e a verdade (1966/1998): "Por nossa posição de sujeito somos sempre responsáveis. Que chamem a isto como quiserem, terrorismo" (p.873).

Lacan faz uma torção no termo terrorismo que permite outro tipo de articulação. Aqui, responsabilidade se insere enquanto implicação do sujeito em relação a si e aos outros, na condição de semelhantes. Essa responsabilidade requer uma participação social que, por vezes, pode resvalar no descumprimento da lei, na medida em que a mesma confronta uma implicação ética por parte do sujeito.

A implicação em relação ao próprio desejo, isso que chamamos aqui de responsabilidade, pode ser nomeada como terrorismo por parte dos poderes já estabelecidos, na medida em que requer um preço que pode resultar em uma acusação.

Entendemos que a disseminação do termo terrorista como a figura do bárbaro não favorece o debate sobre os conflitos entre nações e culturas que tem resultado em embates violentos.

\section{Lei, Ética e Política ou à Guisa de Concluir}

Lembremos que, para Freud (1930/1997), a união e a ordem presentes nas civilizações partem de uma necessidade de segurança. $\mathrm{O}$ argumento de Freud exclui de sua interpretação o bem enquanto causalidade. Assim, a união possibilitada por Eros diz respeito ao amor, mas não às violências típicas aos impostores do bem. Todas as pessoas agem em busca do bem, diz Ferreira (2010). Qual bem? O autor exemplifica modalidades do bem: Inquisição católica, Hitler, Bin Laden, Bush — todos agem pelo bem da humanidade extirpando o mal: “... o equívoco universal a respeito do bem continuará provocando guerras bem-intencionadas em que a razão estará dos dois lados embora não esteja em nenhum. Nenhum dispositivo internacional consegue se impor ao capricho imaginário de alguns tiranos. Quanto aos que são atacados, só resta a resposta das armas” (Ferreira, 2010, p.172).

Nessa direção, Rancière (2016) nos alerta, na entrevista Como sair do ódio?, que debater a política de gestão do sentimento de insegurança é muito diferente de gerir a segurança. Na primeira, o medo e a insegurança são convertidos na "lógica da guerra", incitando à deriva identitária e cheia de ódio. "Se os crimes devem ser tratados pela polícia, o ódio deve ser tratado pela política" (para.06). E completa dizendo que: "Isso implica questionar as causas, os discursos e os procedimentos que engendram o ódio, combater a sério o desemprego, as desigualdades e as discriminações de todo o tipo, e repensar as formas como as pessoas que não vivem e nem pensam do mesmo modo poderiam viver juntas" (para.07). 
Destruir o outro em vez da experiência com o outro e sua diferença está na certeza de uma ignorância — ignorar que o outro é eu —, ou seja: que o odiado no outro é constitutivo do um. O Outro é êxtimo, como sugere Lacan (1959-60/1999), para expressar aquilo que é interior e íntimo, mas que está no exterior. A “exterioridade íntima” (Lacan, 1959-60/1999, p. 143) é a Coisa (das Ding) e também, como sugere anos depois (1969), é algo relacionado ao ponto vazio da estrutura, ao objeto $a$. Trazer aqui essa menção nos serve para reafirmar aquilo que é basal à psicanálise: o sujeito se constitui pelo que é exterior a ele, a exterioridade diz de seu íntimo, não há dentro nem fora, como insiste em mostrar Lacan quando se dedica à topologia.

Seganfredo e Chatelard (2014) sugerem a proximidade entre o êxtimo e o Unheimlich (Freud, 1919/1996), por ambas as palavras apresentarem a qualidade da ambiguidade:

Ambas parecem portar a noção de interior e exterior acontecendo juntos. Ambas são capazes de conjugar o fora e o dentro. Ambas apontam para algo da ordem do real. Êxtimo: o mais íntimo, o mais particular, o mais interior, mas que está excluído, fora. Unheimlich: aquilo que é estranho, estrangeiro e familiar ao mesmo tempo (Seganfredo \& Chatelard, 2014, p. 63).

Por meio da ideia do êxtimo e do Unheimlich encontramos um desenvolvimento do que Freud havia denominado de mecanismo projetivo. A partir desse mecanismo, operamos não só com a ideia daquilo que pertence a um indivíduo e que é atribuído a algum outro, mas também com o sujeito do inconsciente como aquele que existe entre um e outro.

Diante desse mecanismo, podemos compreender que o horror diante do terrorismo que produz fortes imagens de ameaça à civilização ocidental atua no mundo como próprio desejo dos membros dessa sociedade. Não por menos houve certo constrangimento do cinema hollywoodiano logo após o ataque às torres gêmeas. A suspensão de estreias de filmes que apresentavam Nova Iorque sendo destruída não era apenas em respeito às vítimas, mas tratava-se de certa evitação de reconhecer algum vínculo entre o que acontecera e o que membros daquela sociedade vivenciavam em seu psiquismo antes do ocorrido, ou seja, aquilo que imaginavam como possível.

Para que o caráter transubjetivo do terror possa ser exemplificado, podemos nos remeter a um trecho de Clarice Lispector (1978) que demonstra como a aplicação da lei, movida pelo medo e pela evitação, pode produzir reviravoltas. Clarice diz, ao saber que um facínora havia sido morto com treze tiros:

... há alguma coisa que, se me faz ouvir o primeiro e o segundo tiro com um alívio de segurança, no terceiro me deixa alerta, no quarto, desassossegada, o quinto e o sexto me cobrem de vergonha, o sétimo e o oitavo eu ouço com o coração batendo de horror, no nono e no décimo minha boca está trêmula, no décimo primeiro digo em espanto o nome de Deus, no décimo segundo chamo meu irmão. O décimo terceiro tiro me assassina — porque eu sou o outro. Porque eu quero ser o outro (Lispector, 1978, p. 103).

Podemos entender que Lispector assinala o efeito que o ódio nas relações sociais ao outro pode produzir no sujeito, bem como a punição ruidosa que faz com que o representante da lei expie no criminoso aquilo que teme em si. É também nessa direção que cabe ressaltar o insistente trabalho da psicanálise, que consiste em uma tentativa de reinventar a vida com o outro. Não reconhecer o outro, ou tratá-lo somente como uma ameaça a ser exterminada, combatida, nada mais produz que não seja segregação e afetos como os que descrevemos, especialmente o ódio. A lógica de eleger esse 'inimigo' que me impede de ter, ser, conquistar, viver a felicidade e tudo que 'desejo', nada mais faz que desenlace. E, como apontamos na discussão que propusemos, esse afeto de precariedade social é parte de um contexto histórico e político.

Soler (2016) reconhece que os processos de desenlace estão por toda parte e nos diz que a queixa, que traz dois significantes como principais - solidão e precariedade - " "fala do triunfo do individualismo cínico, do declínio de valores universais e da fragilidade dos apegos, quer sejam de casal, de geração ou de vizinhança" (p.9) e lembra a seguinte passagem de Lacan (1967/2003): "Nosso futuro de mercados comuns encontrará seu equilíbrio numa ampliação cada vez mais dura dos processos de segregação" (p. 263). Não que tenha sido em algum momento muito diferente disso. Os exemplos de extermínio e radicalizações racistas e xenófobas estão aí para nos mostrar isso. Mas, talvez, ainda nos caiba insistir em outra possibilidade de futuro.

Rancière (2016), com entusiasmo, diz que não nos faltam ideais, mas 'subjetivações coletivas':

Estamos rodeados de gente que quer salvar o planeta, que vai curar feridos para o outro lado do mundo, que serve comidas a refugiados, que luta por restituir a vida em bairros abandonados. Hoje há muito mais pessoas que se entregam do que no meu tempo. Não nos faltam ideais, faltam-nos subjetivações coletivas. Um ideal é o que incita alguém a encarregar-se dos outros. Uma subjetivação coletiva é o que faz com que todas estas pessoas, juntas, constituam um povo (Rancière, 2016, para.14).

Embora concordemos em que os ideais podem servir como pontos de referência para transformação ou disseminação de qualquer ideia - afinal, é exatamente o que nos mostra o jogo dos ideais que estão postos na 'lógica da guerra' —, é possível que o que nos falte em tempo de segregação e desenlace esbarre muito mais em ética do que na constituição de um Um homogeneizante. 
O que devemos mesmo é aprender como lidar com a diferença, com o outro estranho e próximo a mim. Nesta nossa época, marcada por embates, lutas e diferenças, seja na Europa, seja na América, seja na África, seja em qualquer outro lugar, registramos que o movimento de intensificarmos e mobilizarmos nossas redes de relações é o que possibilitará qualquer tentativa de reinventar o sexual, o social, o político. É o enlace com o outro que pode combater o desenlace administrado pelo Outro.

Com esses elementos podemos retomar a perspectiva de relançar a palavra diante dos discursos radicais atuais, tomando o cuidado de não nos posicionarmos em dicotomias e, assim, convocando a polissemia da palavra.

\section{Referências}

Agamben, G. (2004). Estado de exceção. São Paulo: Boitempo.

Alemán, J. (2013). Sujeto, política: Común. In J. Aleman, Conjeturas sobre una izquierda lacaniana (pp. 13-41). Buenos Aires: Grama ediciones.

Alencar, R. (2012). Por que a Guerra às drogas? Do crack na política ao crack do sujeito (Dissertação de mestrado). Pontifícia Universidade Católica de São Paulo, São Paulo.

Badiou, A. (2016). Nosso mal vem mais de longe. Link

Benjamin, W. (1994). Magia e técnica, arte e política. In W. Benjamin, Obras Escolhidas (Vol. I). São Paulo: Editora Brasiliense.

Clausewitz, C. (2010). Da guerra. São Paulo: Martins Fontes. (Originalmente publicado em 1832).

Descartes, R. (2010). Discurso do método. Porto Alegre: LP\&M. (Originalmente publicado em 1937).

Ferreira, G. A. N. (2010). Doze lições sobre Freud e Lacan. São Paulo: Ponte Editores.

Freud, S. (1976). Delírios e sonhos na Gradiva de Jensen. In J. Stratchey (Ed.), Edição standard brasileira das obras psicológicas completas de Sigmund Freud (Vol. IX, pp.19-93). Rio de Janeiro: Imago. (Originalmente publicado em 1907).

Freud, S. (1996). O estranho. In J. Stratchey (Ed.), Edição standard brasileira das obras psicológicas completas de Sigmund Freud (Vol. XVII, pp.233-269). Rio de Janeiro: Imago Editora.(Originalmente publicado em 1919).

Freud, S. (1997). O mal-estar na civilização. In J. Stratchey (Ed.), Edição standard brasileira das obras psicológicas completas de Sigmund Freud (Vol.XXI, pp.65-147). Rio de Janeiro: Ed. Imago. (Originalmente publicado em 1930).

Freud, S. (1997). Por que a guerra? In J. Stratchey (Ed.), Edição standard brasileira das obras psicológicas completas de Sigmund Freud (Vol.XXII, pp.189-207). Rio de Janeiro: Ed. Imago. (Originalmente publicado em 1932).

Freud, S. (2006). Psicologia de grupo e análise do ego. In J. Stratchey (Ed.), Edição standard brasileira das obras psicológicas completas de Sigmund Freud (Vol.XVIII, pp.77-154). Rio de Janeiro: Ed. Imago. (Originalmente publicado em 1921).

Freud, S. (2006). O futuro de uma ilusão. In J. Stratchey (Ed.), Edição standard brasileira das obras psicológicas completas de Sigmund Freud (Vol. XXI, pp. 11-63). Rio de Janeiro: Imago. (Originalmente publicado em 1927).

Freud, S. (2009). Reflexões para tempos de guerra e morte. Covilha: Universidade da Beira Interior. Link

Fukuyama, F. (1989). The end of history? The National Interest, Summer. Link

Fukuyama, F. (1992). The end of history and the last man. New York: Free Press, 2006.

Lacan, J. (1999). O seminário, livro 7: A ética da psicanálise. Rio de Janeiro: Jorge Zahar. (Originalmente publicado em 1959-60). 
Lacan, J. (1985). O seminário, livro 11: Os quatro conceitos fundamentais da psicanálise. Rio de Janeiro: Jorge Zahar. (Originalmente publicado em 1964).

Lacan, J. (1998). Ciência e Verdade. In J. Lacan, Escritos (pp.869-892). Rio de Janeiro: Zahar, 1995. (Originalmente escrito em 1966).

Lacan, J. (2003). Proposição de 9 de outubro de 1967 sobre o psicanalista da Escola. In J. Lacan, Outros Escritos (pp. 248264). Rio de Janeiro: Jorge Zahar. (Originalmente publicado em 1967).

Lispector, C. (1978). Mineirinho. In C. Lispector, Para não esquecer (pp.101- 103). Rio de Janeiro: Editora Ática.

Michaels, W. B. (1992). Race into culture: A critical genealogy of cultural identity. Critical Inquiry, 18, 684-685.

Mountian, I., \& Rosa, M. D. (2015). O outro: Análise crítica de discursos sobre imigração e gênero. Psicol. USP, 26(2), 152-160. Link

Rancière, J. (2016). Como sair do ódio? Uma entrevista com Jacques Rancière. Revista fórum. Link

Rosa, M. D. (2016). A clínica psicanalítica em face da dimensão sociopolítica do sofrimento. São Paulo: Escuta/FAPESP.

Rosa, M. D., Carignato, T. T., \& Berta, S. (2006). Ética e política: A psicanálise diante da realidade e dos ideais contemporâneos. Ágora: Estudos em Teoria Psicanalítica, 9(1), 35-48.

Safatle, V. (2002). “A política do real de Slavoj Zizek” (Pósfácio), In S. Žižek, Bem-vindo ao deserto do real. São Paulo: Boitempo.

Seganfredo, G., \& Chatelard, D. (2014). Das Ding: O mais primitivo dos êxtimos. Link

Soler, C. (2016). O que faz laço? São Paulo: Escuta.

Žižek, S. (1996). Como Marx inventou o sintoma? In S. Žižek (Org.), Um mapa da ideologia (pp. 297-331). Rio de Janeiro: Contraponto.

Žižek, S. (1997). The abyss of Freedom/Ages of the world. Ann Arbor: University of Michigan Press.

Žižek, S. (2015). Perturbação numa redoma. Link

\section{Endereço para correspondência}

Miriam Debieux Rosa

Email: debieux@terra.com.br

Patícia do Prado Ferreira

Email: patricia.ferreiralemos@gmail.com

Rodrigo Alencar

Email: r.alencar@gmail.com 